\title{
Jocular mockery as interactional practice in everyday Anglo-Australian conversation
}

\author{
Michael Haugh \\ Griffith University
}

\begin{abstract}
Teasing in everyday interactions, which combines elements of (ostensible) provocation and (ostensible) playfulness in a figurative cutting down or diminishment of a target, has been the subject of a growing body of studies. However, what has arguably not been as well studied to date is the interactional mechanics of the different kinds of social actions through which teasing is accomplished. In this paper, the way in which teasing as mocking/ridiculing can be accomplished within a jocular or non-serious frame, or what is here termed jocular mockery, is examined building on methodological and analytical insights from both interactional pragmatics and corpus-assisted pragmatics. It is argued based on this analysis that jocular mockery constitutes a recognisable and recurrent practice in everyday interactions amongst (Anglo-)Australian speakers of English. A framework for examining the dynamics of jocular mockery within everyday interactions is also proposed.
\end{abstract}

\section{Key words}

teasing, mocking, Australian English, interactional pragmatics, corpus-assisted pragmatics

\section{Introduction}

Teasing in everyday interactions involves a figurative cutting down or diminishment of a target, with such mocking jibes or taunts often being framed as playful or humorous by participants (Drew 1987). However, from the ever growing body of studies on teasing it has emerged that teasing in fact encompasses a markedly heterogeneous group of social practices. What appears to be in common across this diverse range of practices is that teasing combines elements of (ostensible) provocation and (ostensible) playfulness. The myriad of ways in which this provocation and playfulness can be occasioned and combined in interaction by participants is what underpins the multitude of interpersonal functions that have been ascribed to it by researchers. These include teasing for the sake of amusement or entertainment of the participants, if not for the target him/herself (e.g. Haugh and Bousfield 2012; Yu 2013), fostering interpersonal solidarity in order to maintain individual relationships and in-groups, alongside excluding others thereby creating out-groups (e.g. Adetunji 2013; Blythe 2012; Boxer and Cortés-Conde 1997; Butler 2007; Haugh 2010a, 2011; Norrick 1993; Straehle 1993), claiming or ascribing identities (e.g. Drew 1987; Queen 2005; Schnurr 2009), defusing conflict and mitigating potential offence or embarrassment (e.g. Dynel 2007; Norrick and Spitz 2008; Yu 2013), as well as indicating moral transgressions (e.g. Drew 1987; Everts 2003; Franzén and Aronsson 2013), asserting interpersonal power (e.g. Norrick 1994; Partington 2008; Schnurr 2009), and for expressing outright aggression or bullying (e.g. Harwood 2010; Keltner et al. 2001; Kotthoff 1996). Yet given the wide range of potential interpersonal - and sometimes intergroup - functions attributed to teasing, it is perhaps surprising that the social actions or practices by which these pragmatic effects are realised has been somewhat neglected. This lack of attention to the social actions underpinning teasing has arguably limited our understanding of the mechanics of teasing in social interaction (Blythe 2012: 508). ${ }^{1}$

\footnotetext{
${ }^{1}$ Although see Béal and Mullan’s (forthcoming) framework for analysing conversational humour more broadly.
} 
In light of the fact that teasing encompasses a heterogeneous range of practices and interpersonal functions, it appears that one way to deepen our understanding of teasing as an object of study is to examine the ways in which the different social actions that give rise to teasing are themselves accomplished in situated interactions. In this paper, the focus will be primarily on one type, namely, teasing that is accomplished through mocking or ridiculing. In particular, the analysis will centre on mockery that is accomplished within jocular or nonserious frames, or what has previously been termed “jocular mockery” (Haugh 2010a, 2011; Haugh and Bousfield 2012), although the ways in which such playful or jocular mockery can slip into "annoying/irritating” or even "provoking/goading” (at least from the perspective of some of the participants) will be briefly considered. ${ }^{2}$

The paper begins in the following section by first discussing in more detail what constitutes jocular mockery and how it can be identified as it arises in situated interactions within an interactional pragmatics paradigm, which is an approach to pragmatics informed by research and methods in ethnomethodological conversation analysis (Arundale 2010; Haugh 2010a, 2012). Drawing from methods in corpus-assisted pragmatics (Partington 2008; Béal and Mullan forthcoming), it is next argued, based on a preliminary survey of candidate examples of jocular mockery drawn from various corpora of spoken interaction available through the Australian National Corpus (http://www.ausnc.org.au), that it constitutes a recurrent and recognisable practice in interactions amongst Australian speakers of English. The range of targets of jocular mockery and the various responses to jocular mockery open to participants are then explored in more detail, which subsequently grounds the proposal of a model for examining the interactional dynamics of jocular mockery. Finally, the implications for the analysis of jocular mockery as a form of interactional practice, and for corpus-assisted pragmatics more broadly, are briefly considered in the conclusion.

\section{Design and response features of jocular mockery}

Jocular mockery has been defined as social actions (as opposed to simply (non)verbal acts) whereby the speaker somehow diminishes something of relevance to self, other, or a non-copresent third party, but does so within a non-serious or playful frame (Haugh 2010a: 2108). This builds on the ordinary sense of mock as meaning to "deride" or "make fun of" someone or something. The figurative cutting down or diminishment of the target achieved through this mockery is ostensibly provocative, but in being framed as playful or affable, puts considerable moral pressure on the target to treat it as jocular, and so not to be taken (too) seriously (see also Fox 2004: 68; Goddard 2006, 2009; Norrick 1993: 80). Candidate examples of jocular mockery can thus be identified through close interactional analysis of both how mockery is framed as non-serious or jocular by speakers through particular design features, and the ways in which it is treated as such by respondents through their subsequent uptake.

Mockery can be projected within a non-serious or humorous frame, and thus as a "laughable", in a number of ways, including through various combinations of laughter particles, prosodic or phonetic cues, lexical exaggeration, implicit contrasts with known facts, formulaicity and topic shift markers, as well as facial or gestural cues (Haugh 2010a), as has been noted in studies of teasing and improprieties more generally (Blythe 2012; Drew 1987; Jefferson, Sacks and Schegloff 1987; Holt 2007; Straehle 1993; Sidnell 2011).

These design features of jocular mockery are summarised in Table 1 below.

\footnotetext{
${ }^{2}$ Cf. earlier work by the author, which has emphasised the ways in which relationships between participants are co-constituted through jocular mockery (Haugh 2010a, 2011), or focused on how it may give rise to evaluations of (mock) impoliteness (Haugh 2011; Haugh and Bousfield 2012).
} 
Table 1: Summary of design features of jocular mockery

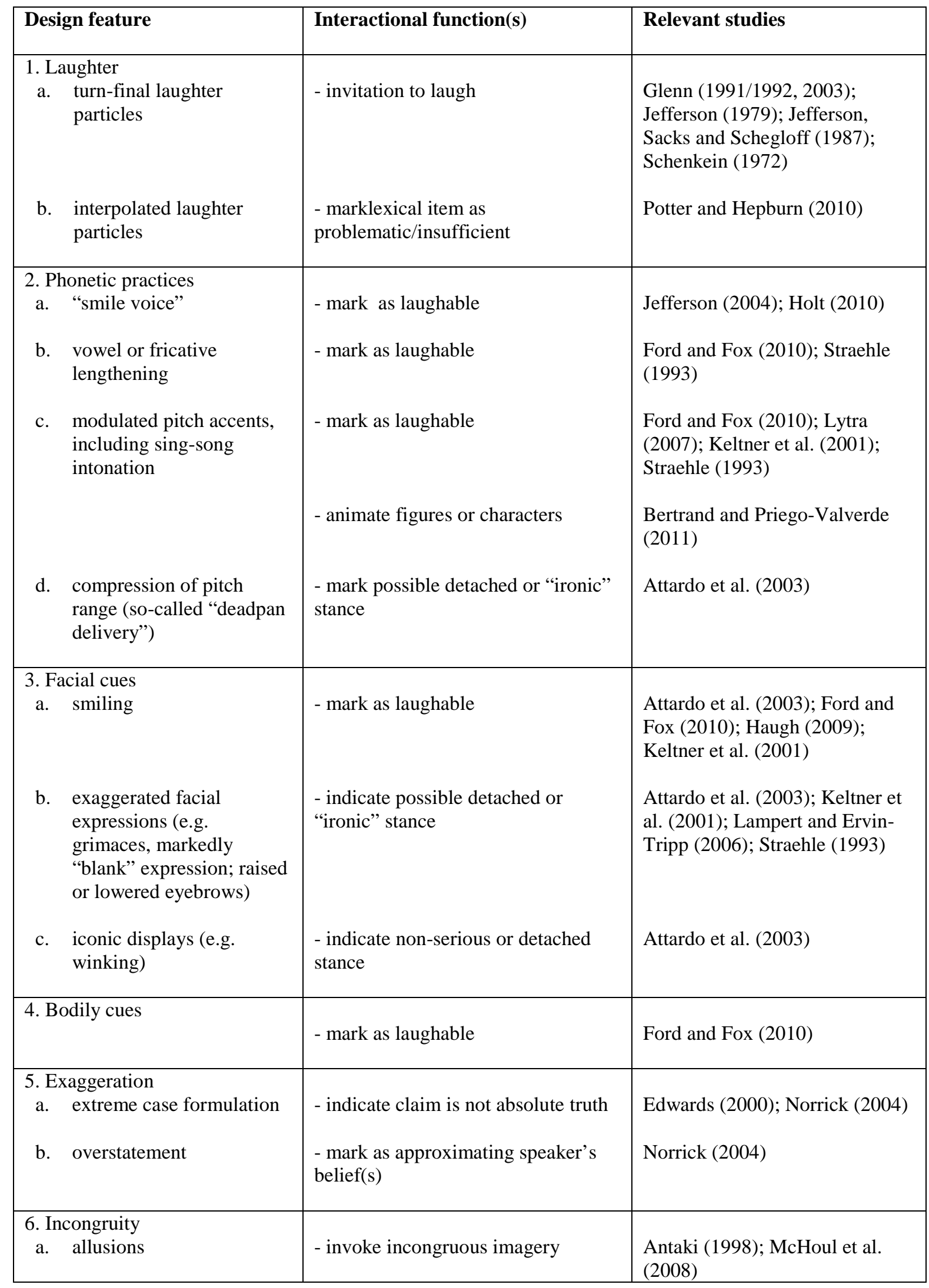




\begin{tabular}{|l|l|l|}
\hline b. presuppositions & - create implicit contrast(s) & Drew (1987); Edwards (2000) \\
\hline 7. Formulaicity & $\begin{array}{l}\text { - indicate shift in register } \\
\text { - indicate closing of (non-serious) } \\
\text { sequence }\end{array}$ & Straehle (1993) \\
\hline 8. Topic shift markers and Holt (1998) \\
\hline $\begin{array}{l}\text { - indicate beginning of (serious) } \\
\text { sequence }\end{array}$ & Drew (1987); Schegloff (2001) \\
\hline
\end{tabular}

In the first instance, mockery can be marked as non-serious or jocular through postutterance completion laughter particles that invite other participants to join in with laughter (Glenn 1991/1992, 2003; Jefferson 1979; Jefferson, Sacks and Schegloff 1987; Schenkein 1972). As Potter and Hepburn (2010) note, laugh particles can also be interpolated within words, in which case they mark the lexical item as somehow problematic or insufficient, and thus open to mockery. Yet while laughter on the part of the speaker is a recurrent feature of jocular mockery, as Holt (2010, 2011) rightly points out, laughter does not necessarily on its own constitute jocularity, and indeed multiple other interactional resources are drawn upon in constructing a turn as "laughable" (Ford and Fox 2010; Haakana 2002).

Various phonetic and prosodic features can also mark mockery as non-serious, and thus potentially one that can be treated as a laughable. So-called "smile voice", where laterally spread lips lend a "smiling" quality to the voice (Ford and Fox 2010), can be used to mark the action, here mockery, as potentially laughter relevant (Jefferson 2004b; Holt 2010). Other phonetic design features of jocular mockery encompass vowel or fricative lengthening, as well as modulations in pitch, including so-called "sing-song" intonation, by which speakers animate a particular figure within their talk (Bertrand and Priego-Valverde 2011), or mark the action as potentially laughter relevant (Ford and Fox 2010; Lytra 2007; Keltner et al. 2001; Straehle 1993).

There are also various facial cues by which participants can frame mockery as non-serious as well, including through smiling, raised or lowered eyebrows, and other exaggerated facial expression, including grimaces and markedly "blank" expressions, and closely related iconic displays, such as winking (Attardo et al 2003; Haugh 2009; Keltner et al. 2001; Lampert and Ervin-Tripp 2006; Straehle 1993). According to Ford and Fox (2010), other embodied displays by which an action is framed as a laughable include participants leaning back, covering their face with their hand(s), clapping their hands or slapping a surface, among others.

Linguistic indicators of jocular mockery include exaggerated, incongruous and formulaic expressions, as well as various topic shift markers. Exaggerated expressions include what Pomerantz (1986) original termed "extreme case formulations", such as all, always, every, never, none, by means of which speakers mark something is to be taken "non-literally", and thus the veracity of claim or assessment being made is something for which they cannot be held accountable (Edwards 2000; Norrick 2004). Closely related to these are what Norrick (2004) terms "overstatements", where "the speaker makes a claim higher (or lower) on some scale than warranted" (p.1729). In this way the speaker can mark the belief or assessment in question as "approximated", and so open to revision (and thus also open dispute by other participants). Closely related to exaggeration is the occurrence of incongruity, either through allusions to incongruous imagery (Antaki 1998; McHoul et al. 2008), or through an implicit contrast with what is presupposed or known amongst those participants (Drew 1987; Edwards 
2000). However, the assumption that non-serious or jocular mockery is always directed towards matters that are known to be untrue by participants (e.g. Leech 1983: 144-145; Culpeper 1996: 352), has since proven to be somewhat of an over-generalisation, as in some cases mockery has been found to constitute a means by which serious remarks are posed as non-serious or jocular (Grainger 2004; Haugh and Bousfield 2012; Mills 2003: 124).

Finally, various formulaic expressions may index a shift in register (Straehele 1993), as well as indicating the closing of a non-serious sequence (Drew and Holt 1998). The beginning of a sequence which contrasts in some way with that of prior one can also be marked through lexical markers of discontinuity, including through topic-initial 'no' (Drew 1987; Schegloff 2001). Such a shift back to a serious frame can constitute evidence for the participants that the prior mockery was part of a non-serious insert sequence, or in some cases post-expansion sequence, to the main (serious) interactional activity at hand (Schegloff 2001, 2007). ${ }^{3}$ However, it is important to note that while jocular mockery more often than not occurs in insert or post-expansion sequences that are framed as non-serious, this is not to say these mocking remarks interrupt the progressivity of the ongoing "serious" interactional business (Stivers and Robinson 2006), and, indeed, in some cases the jocular mockery in fact contributes to the advancement of that main agenda.

Close examination of the responses to the mockery by other participants, including both the target of the mockery or other participants when co-present, is also critical for establishing that it is being treated as non-serious or jocular by those participants (Haugh 2010a; see also Drew 1987; Dynel 2008; Keltner et al. 2001; Pawluk 1989; Straehle 1993).

The various ways in which mockery can be treated as non-serious or jocular are summarised in Table 2 below.

Table 2: Summary of response features of jocular mockery

\begin{tabular}{|c|c|c|}
\hline Response feature & Interactional function(s) & Relevant studies \\
\hline 1. Laughter & $\begin{array}{l}\text { - mark as laughable } \\
\text { - indicate appreciation }\end{array}$ & $\begin{array}{l}\text { Drew (1987); Everts (2003); Glenn (2003); Holt } \\
\text { (2010); Jefferson et al. (1987) } \\
\text { Beach and Glenn (2011); Drew (1987); Everts } \\
\text { (2003); Glenn 2003; Jefferson et al. (1987); } \\
\text { Sidnell (2011) }\end{array}$ \\
\hline 2. Explicit accord & - indicate agreement & Drew (1987) \\
\hline 3. (Partial) repetition & $\begin{array}{l}\text { - indicate appreciation } \\
\text { - indicate agreement }\end{array}$ & $\begin{array}{l}\text { Drew (1987); Jefferson et al. (1987) } \\
\text { Drew (1987) }\end{array}$ \\
\hline 4. Elaborating on mockery & $\begin{array}{l}\text { - indicate appreciation } \\
\text { - indicate agreement }\end{array}$ & $\begin{array}{l}\text { Drew (1987); Jefferson et al. (1987) } \\
\text { Drew (1987) }\end{array}$ \\
\hline
\end{tabular}

\footnotetext{
${ }^{3}$ In a few cases, a chain of mocking remarks arguably constitutes a sequence in its own right, that is, where the main interactional business is simply the participants entertaining themselves rather than some attendant “serious” interactional project.
} 


\begin{tabular}{|l|l|l|}
\hline 5. Countering mockery & - indicate appreciation & Drew (1987); Dynel (2008); Norrick (1993) \\
\hline
\end{tabular}

One of the key means by which mockery is treated as non-serious, and thus potentially jocular, by participants is through laughter by one or more the recipients (Beach and Glenn 2011; Drew 1987; Everts 2003; Glenn 2003; Holt 2010; Jefferson, Sacks and Schegloff 1987; Sidnell 2011). Treating the mockery as non-serious through laughter does not, of course, mean that recipients are always accepting or going along with it, or that they are treating is as humorous per se, as laughter may be associated with serious rejection or resistance to mockery (Drew 1987; Glenn 2003), or even with topic termination (Holt 2010, 2011). Careful analytic attention is thus required in dealing with laughter responses given that laughter constitutes an action in its own right (Holt 2011). Indeed, as Glenn (2003) argues, there is an important difference for participants, particularly the target of the mockery, between laughing with and laughing at someone.

Other key ways in which recipients display interpretations of mockery as jocular is through displaying explicit agreement with or appreciation of the mockery, either through explicit agreement, (partial) repetition of the mocking remark, or through a continuation of the jocular frame by another participant elaborating upon the mockery or countering it (Drew 1987; Jefferson, Sacks and Schegloff 1987). The latter sequences where participants elaborate on or counter (usually just) prior instances of jocular mockery with further instances of jocular mockery constitute what is commonly referred to as "banter" in the literature (Dynel 2008: 243; Leech 1983: 144-145; Norrick 1993: 29).

It is clear, then, that in identifying candidate examples of jocular mockery, close analysis of the ways in which participants contribute to the accomplishment of mockery in local sequential contexts both through interactional design and response is required. Having established the key design and response features of jocular mockery, we now move to consider the question of whether it constitutes a recognisable and recurrent practice in everyday or mundane interactions. In the following section, this question is explored by first outlining how a collection of candidate examples of jocular mockery was assembled drawing from four different corpora of spoken interaction amongst Anglo speakers of Australian English, three of which are currently available through the Australian National Corpus, and then summarising the main features of that collection.

\section{Jocular mockery as interactional practice}

Following standard practice in corpus pragmatics, and indeed pragmatics more broadly, any analysis of the practices by which social actions are accomplished begins with assembling a collection of candidate examples of the observed phenomenon in question. In this study, in order to identify candidate examples from as wide a range of situated contexts as possible, the collection in question was assembled from a variety of different corpora of Australian English. Candidate examples were taken from fifty conversations between family and friends sourced from the Australian component of the International Corpus of English (ICE-AUS) and the Griffith Corpus of Spoken Australian English (GCSAusE) (approximately 550 minutes of audio-recordings and associated transcripts), five recordings from radio talkback programmes from the Australian Radio Talkback corpus (ART) (approximately 200 minutes of audio-recordings and associated transcripts), all of which are now freely available through the Australian National Corpus (www.ausnc.org.au). This was supplemented by candidate examples taken from eighteen conversations between unacquainted Australians, the Australians Getting Acquainted corpus (AGA) collected by the author (approximately 200 minutes), and seven conversations between married couples (approximately 300 minutes) 
(Gardner 2002). In the case of transcripts taken from ICE-AUS and ART, further paralinguistic details were added to these based on repeated listenings to recordings according to standard CA transcription conventions (Jefferson 2004; Hepburn and Bolden 2012). ${ }^{4}$

The key advantage of this corpus-assisted approach to assembling this collection of candidate examples was that these instances are drawn from a wide range of different kinds of mundane, everyday interactions beyond what a single researcher might realistically collect. The candidate examples were drawn from interactions ranging from "private" conversations between relational intimates (i.e. couples), families and friends (GCSAusE; ICE-AUS), as well as persons who are only just getting acquainted (AGA), through to "public" interactions conducted in front of an "overhearing" audience between persons whose relationships varied from acquaintanceship through to being as yet unacquainted (ART). The wide range of mundane everyday interactional settings in which candidate examples of jocular mockery can be found is what grounds the claim made in this section that it constitutes a recognisable and recurrent interactional practice amongst Australian speakers of English.

After close qualitative analysis - based on the design and response features of jocular mockery outlined in the previous section - of the collection of candidate examples of jocular mockery that was assembled from these various corpora, a collection of 135 examples of jocular mockery arising in 93 separate interactional sequences was established. These 135 instances were initially sorted according to the target of the mocking remarks. As Haugh (2010a) notes, jocular mockery can be directed by the speaker at him or herself (self-directed jocular mockery), at another co-present participant (other-directed jocular mockery), or at a non-co-present third party (third party-directed jocular mockery), as illustrated in the two examples below.

(1) ICE-AUS: S1A-004: 1:50

61 B: that looks supe:rb mum.

62 P: $\downarrow$ go: od $=$

63 B: =it re:ally does.

64 P: look all right (.) or.

$65 \quad B: \quad=m m m$

66 P: two four six eight (.) looks good enough-

67 good enough to eat.

$68 \quad(0.2)$

69 E: almost.

70 P: Good enough to eat

(2) ART: ABCnat2: 10:49

1 R: Compound wo:rds which are (.) $\uparrow$ really very

2 <efficient> (0.4) as you'd expect.

$3 \quad(0.3)$

4 T: but they do- they do irritate the reviewers

5 of the T L S though hhh heh=

6 R: =ha ha ha ha ha

In example (1), Beryl compliments her mother, Patty on the dinner she has just served. This occasions an instance of self-directed jocular mockery in lines 66-67, where by characterising the dinner as "good enough to eat", she implies that it might not actually be as good as it looks. This is followed by an instance of other-directed jocular mockery when

\footnotetext{
${ }^{4}$ The author would like to thank Rod Gardner for generously offering access to his collection of recordings and CA transcripts, and Pam Peters for kindly offering access to audio recordings from the ICE-AUS and ART corpora (the latter being not yet freely available through the Australian National Corpus due to ethical and legal restrictions).
} 
Eddie elaborates on the just prior self-directed mockery through hyper-understanding (Brône 2008), that is, where a next speaker "exploit[s] potential weak spots (ambiguity) in a previous speaker's utterance by echoing the latter's words with a fundamentally different reading” (p.2028); in this case, that the dinner is "almost" but not actually good enough to eat (turn 69). In example (2), which is an excerpt from a radio programme where the Australian author, Tim Winton, is being interviewed, Winton mocks the reviewers of the Times Literary Supplement (TLS) as the sort of people who take the importance of "correct” English (e.g. avoiding compound words) far too seriously. It thus constitutes an instance of (non-copresent) third party-directed jocular mockery.

Mockery can also be directed at objects, places or situations (i.e. object/place/situationdirected jocular mockery) as seen in example (3) below.

(3) GCSAusE02: 0:14

$\begin{array}{lll}12 & \text { T: } & \text { ye:ah look, look at the myspace badge } \\ 13 & & \text { that spencer got - I got one } \\ 14 & & \text { as well but it's at work [hah?] } \\ 15 & \text { A: } & \text { [hh ] } \\ 16 & & (0.5) \\ 17 & \text { T: } & \text { who the fuck would ever [wear that?] } \\ 18 & \text { A: } & \end{array}$

In this excerpt, Tony is talking with Alfie about a "myspace" badge that a mutual friend has got (lines 12-13), and then admits he has one himself (lines 13-14), but then goes on to deliver a mocking negative assessment of it (line 17). However, while the latter target of jocular mockery is ostensibly not directed at persons, it can nevertheless have implications for persons in cases where the object, place or situation in question is one with which one or more participants might align themselves through ownership or some other connection with the target in question. In this case, then, it has implications for a non-co-present third-party (Spencer), as well as the speaker himself for purchasing such an item

The number of instances of jocular mockery sorted relative to the target of the mocking remark across the four main collections are summarised in Table 3 below.

Table 3: Targets of jocular mockery

\begin{tabular}{|l|c|c|c|c|c|}
\hline & AGA & ART & GCSAusE & ICE-AUS & Total \\
\hline self-directed & $24(51 \%)$ & $10(28 \%)$ & $5(25 \%)$ & $7(22 \%)$ & $46(34 \%)$ \\
\hline other-directed & $14(30 \%)$ & $23(64 \%)$ & $9(45 \%)$ & $15(47 \%)$ & $61(45 \%)$ \\
\hline third party-directed & $4(8.5 \%)$ & $2(5.5 \%)$ & $1(5 \%)$ & $4(12.5 \%)$ & $11(8 \%)$ \\
\hline $\begin{array}{l}\text { object/place/situation- } \\
\text { directed }\end{array}$ & $5(10.5 \%)$ & $1(2.5 \%)$ & $5(25 \%)$ & $6(18.5 \%)$ & $17(13 \%)$ \\
\hline Total & 47 & 36 & 20 & 32 & 135 \\
\hline
\end{tabular}

As can be seen, the majority of instances of jocular mockery were either self-directed (34\%) or other-directed (45\%). A smaller minority of instances were directed at non-co-present third parties (8\%), or at objects, places or situations/events (13\%). What is also notable here is that jocular mockery arose not only in mundane interactions between participants who were friends or even family members (i.e. 52 instances in GCSAusE and ICE-AUS), but also in interactions between people who were getting acquainted (i.e. 47 instances in AGA), as well as in public interactions between people who were already acquainted in some cases and only 
just getting acquainted in others (i.e. 36 instances in ART). An interesting pattern to emerge vis-à-vis the targets of jocular mockery was that in "private" interactions where participants were getting to know each other a greater proportion of the targets of jocular mockery were self-directed as we can see when examining the relative frequency of instances in AGA (51\% self-directed; 30\% other-directed; $19 \%$ not directed at co-present participant), while in "private" interactions where the participants knew each other this pattern was reversed when we examine the combined relative frequency of instances in GCSAusE and ICE-AUS (23\% self-directed; $46 \%$ other-directed; 31\% not directed at co-present participant). The third broad context type, namely, "public" interactions broadcast on radio talkback revealed an even stronger tendency towards other-directed jocular mockery (64\%), with $28 \%$ being instances of self-directed jocular mockery, and just $8 \%$ being non-co-present third party or object/place/situation-directed. These tendencies appear to be a result of contextual constraints (e.g. on radio talkback where there is a large "overhearing” audience there is less ready recourse to objects in the immediate surroundings or commonly known places or events), as well as the various interactional work accomplished through jocular mockery in different situated contexts (e.g. for the sake of amusement or entertainment of participants, including the "overhearing" audience in the case of ART, fostering interpersonal solidarity or establishing passing relational in- or out-groups amongst participants).

The range of responses to instances of jocular mockery were then examined in this collection of 135 examples of jocular mockery. Building on Drew's (1987) typology of responses to teases, responses from other participants to mocking remarks were categorised into five broad types:

(1) rejection of the mockery
a. laughing rejection
b. po-faced rejection

(2) going along with the mockery

a. laughing appreciation

b. laughing acceptance

(3) elaborating the mockery

(4) reciprocating or countering the mockery

(5) not verbally attending to the mockery

In the case of rejecting what was proposed in the mockery, participants either delivered the rejection with concomitant laughter or responded in a po-faced manner, that is, in a way that made it evident the rejection was serious without treating it as a laughable (although notably other participants often treated it as a laughable in such cases). In going along with the mockery, participants either simply expressed appreciation through laughter or indicated acceptance of what has been mockingly proposed through laughter accompanied by explicit accord (i.e. yes-like responses) or (partial) repetition of the mocking remark. In some cases the jocular mockery was extended into a "banter" sequence either through elaboration of the mockery by other participants, or reciprocating the mockery (in the case of self-directed jocular mockery) or countering the mockery (in the case of other-directed jocular mockery). ${ }^{5}$ Finally, in a number of cases the mocking remark was not attended to in any audible way by participants, although given the corpora in question only had audio recordings associated with them, it remains an open question as to whether there were any non-verbal responses in those cases. Thus rather than classify these as instances of ignoring the tease (see Drew 1987:

\footnotetext{
${ }^{5}$ As briefly noted above, the 135 instances of jocular mockery were found in 93 interactional sequences, thus indicating that a large proportion of instances arose in such banter sequences. The analysis of jocular mockery vis-à-vis banter lies outside of the scope of this paper, however, due to constraints of space.
} 
$228,230)$, the analytical equivocality here was reflected in the choice to simply categorise them as instances of participants not verbally attending to the jocular mockery. ${ }^{6}$

Responses to the 135 instances of jocular mockery in this collection are summarised in Table 4 below.

Table 4: Responses to jocular mockery

\begin{tabular}{|l|c|c|c|c|c|}
\hline & self-directed & $\begin{array}{c}\text { other- } \\
\text { directed }\end{array}$ & $\begin{array}{c}\text { third party- } \\
\text { directed }\end{array}$ & $\begin{array}{c}\text { object/place/ } \\
\text { situation-directed }\end{array}$ & Total \\
\hline reject & $2(4 \%)$ & $21(28 \%)$ & $4(28.5 \%)$ & $4(20 \%)$ & $31(19 \%)$ \\
\hline go along with & $28(52 \%)$ & $28(38 \%)$ & $7(50 \%)$ & $11(55 \%)$ & $74(46 \%)$ \\
\hline elaborate & $10(18.5 \%)$ & $13(17.5 \%)$ & $3(21.5 \%)$ & $5(25 \%)$ & $31(19 \%)$ \\
\hline counter/reciprocate & $4(7 \%)$ & $1(1.5 \%)$ & $0(0 \%)$ & $0(0 \%)$ & $5(2 \%)$ \\
\hline disattend & $10(18.5 \%)$ & $11(15 \%)$ & $0(0 \%)$ & $0(0 \%)$ & $21(13 \%)$ \\
\hline Total & 54 & 74 & 14 & 20 & 162 \\
\hline
\end{tabular}

As can be seen there were 162 different responses identified. This is a function of the fact that a number of the interactions were multi-party conversations, and so multiple responses to the one instance of jocular mockery were likely. However, even in dyadic conversations (i.e. between two participants), multiple responses were possible, given respondents could elect to combine responses (e.g. laughing appreciation with an elaboration). One notable finding across these corpora is that responses to self-directed jocular mockery were overwhelmingly ones where other participants either were going along with it (52\% of responses) or were elaborating on it (18.5\%), with the latter simultaneously constituting an instance of otherdirected jocular mockery that has been occasioned by the prior self-directed jocular mockery. A small proportion of responses to self-directed jocular mockery involved either rejection (4\%) or reciprocation through self-directed jocular mockery on the part of another participant (7\%). In the case of other-directed jocular mockery, the proportion of responses where participants were going along with it (38\%) or elaborating on it (17.5\%) was still relatively high, with notably, some instances of the latter involving self-directed mockery in cases where the target of the other-directed mockery him or herself responded through elaboration. ${ }^{7}$ However, the proportion of responses where the mocking remark was rejected was higher overall for other-directed jocular mockery than for self-directed jocular mockery (28\% in the case of the former and $4 \%$ in the case of the latter). A roughly similar pattern to that for responses to other-directed jocular mockery was found for responses to jocular mockery directed at non-co-present third parties and objects/places/situations. These overall differences likely reflect systematic differences in the multiple constraints on responses to self-directed versus other-directed jocular mockery (i.e. the preference to agree or disagree with the prior speaker's mocking stance versus the preference to go along with the jocular frame) (see also Drew 1987).

\footnotetext{
${ }^{6}$ The role of non-verbal responses to jocular mockery thus remains an open question requiring further study.

${ }^{7}$ Detailed analysis of responses of the target(s) as opposed to non-targets to other-directed jocular mockery lies outside of the scope of the current analysis, although preliminary analysis indicates a greater proportion of rejecting responses were initiated by the target (roughly 85\%), a greater proportion of elaborative responses were initiated by other non-target participants (roughly $80 \%$ ), and roughly similar proportions of responses going along with the mocking tease were found across target and non-target participants.
} 
Overall, then, the majority of responses to self-directed and other-directed jocular mockery were ones where participants were going along with or elaborating on the mocking remark, although in the latter case close to a third of responses also constituted some form of rejection of what had been proposed through the mockery. It can thus be seen that although what has been proposed in the mocking remark be rejected by participants, particularly in the case of other-directed jocular mockery, there is a clear trend is for participants (including both targets and non-targets of the mockery) to treat the mockery as non-serious or jocular through going along with the mockery or elaborating on it. The claim that there is a widespread expectation amongst speakers of Anglo varieties of English that participants will respond to mockery that is framed as jocular or non-serious in a non-serious way (Fox 2004; Goddard 2006, 2009; Norrick 1993) thus seems to be borne out in the current analysis.

In this survey of a collection of examples of jocular mockery preliminary evidence has been presented that it is a recurrent practice across various different situated contexts, ranging from public and private interactions between persons getting acquainted through to private interactions between family and friends. It was also found to arise across various age groups and across genders, as we can also see from the examples discussed in the following section. The analysis of responses to jocular mockery has also indicated preliminary evidence of an expectation that mockery framed as jocular or non-serious be treated as such by other participants, including the target(s). On those grounds, then, it can be suggested that jocular mockery constitutes not only a recurrent but also a recognisable practice in interactions amongst (Anglo-)Australian speakers of English.

In the following section, we explore in further detail the ways in which jocular mockery arises concomitant with both the serious and non-serious business of interaction in moving towards a tentative model for examining the interactional dynamics of jocular mockery.

\section{The interactional dynamics of jocular mockery}

It was briefly noted in offering a preliminary definition of jocular mockery at the beginning of section two that it can be directed at others, self, non-co-present third parties, and objects/places/situations. In this section, examples of other-directed jocular mockery (example 4), self-directed jocular mockery and third party-directed jocular mockery (example 5), and object-directed jocular mockery (example 6) are each discussed in turn, with a particular focus on the design and response features typical of these different interactional targets, as well as the various response options open to participants.

In the following excerpt from a radio broadcast where the Australian author Tim Winton is being interviewed about his (then new) novel "Cloudstreet", listeners to the programme have been invited to call in and ask the author questions. In this particular excerpt, other-directed jocular mockery is occasioned when the caller announces she is a year twelve student (in high school) who is studying that novel.

(4) ART: ABCnat2: 25:34

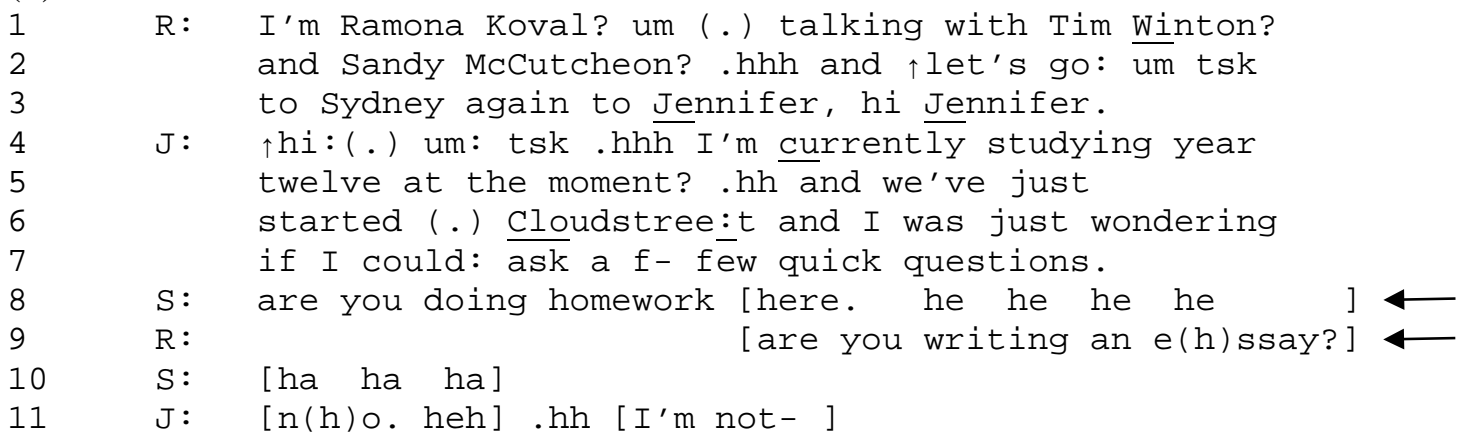




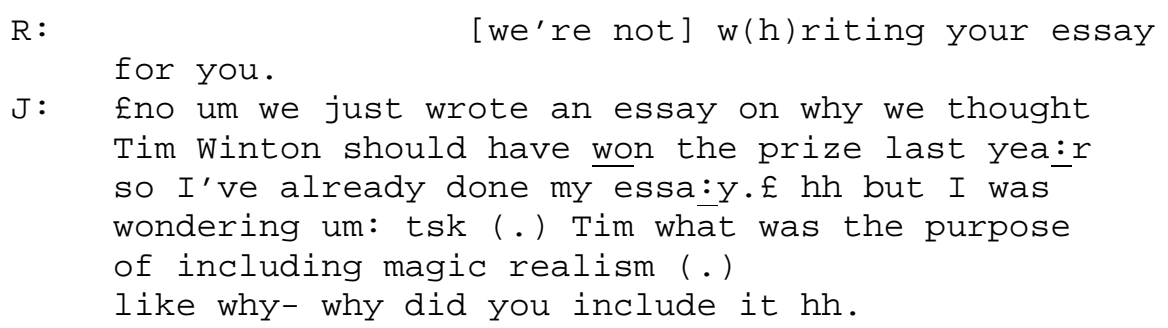

Jennifer begins her call in lines 4-7 with a recognisable pre sequence or "pre-asking" (Schegloff 2007), that is, where she projects a forthcoming request for information in such a way that she orients the addressee, here Tim Winton, to what would count as a relevant responses (given she is a year twelve high school student). However, rather than occasioning a "go-ahead" response, the second presenter, Sandy, proffers a tease where he makes fun of Jennifer in suggesting that she has an underlying agenda here, namely, getting tips for her homework (line 8), thereby exploiting potential ambiguity as to the interactional "project" at play here (Levinson 2012: 118). That this mockery is framed as non-serious is evident from the utterance post-completion particles where Sandy invites the other participants to laugh, as well as the incongruity occasioned by mention of "doing homework" in the context of a national broadcast about a famous novelist's latest work. The mockery is elaborated upon by the other presenter, Ramona, when she suggests through her question in line 9 that Jennifer's agenda is in fact writing an essay, and goes on to ostensibly rebut this alleged agenda in line 12 in claiming they will not be doing such a thing. The appearance of laughter particles interpolated into "essay" (line 9) and "writing” (line 12), or what Potter and Hepburn (2010) term "interpolated aspiration particles" (IPA), here soften the mocking remarks somewhat, and also display sensitivity as to how Jennifer might receive these teases (p.1552), thereby implicitly framing them as non-serious. What is notable about this other-directed jocular mockery here is that it occasions an elaboration of the mockery by another participant who is not in this instance the target.

The two instances of mockery are also treated as non-serious and indeed jocular by the other participants. Sandy displays appreciation of Ramona's tease through laughter in line 10, and the target of the mockery, Jennifer, also responds with laughter (line 11). However, although the latter (seriously) rejects the attribution of this underlying agenda (both in an aborted attempt in line 11 and re-started and completed from line 14 onwards), and so her response is characterisable as "po-faced” on Drew's (1987) approach, this rejection is delivered with a "smiley voice" (i.e. suppressed laughter). Through this suppressed laughter, Jennifer acknowledges the prior laughter (Jefferson 2004b: 128), thereby treating the suggestion of an underlying agenda as constituting something laughable (Holt 2011), but also displays that her response is disaffiliative with that stance (Greer et al. 2005). Notably, the IPAs in her explicit rejection (i.e. "n(h)o") in turn 6, also softens this correction and displays reciprocal sensitivity towards Ramona (and Sandy) as to how they might receive her response to their teasing. Jennifer then marks a shift back to a serious frame of doing questioning through a contrastive particle ("but") and alluding to her original pre-asking (i.e. "I was wondering”) in formulating her question, thereby constituting further evidence that the participants are treating this as a jocular insert sequence (Schegloff 2001, 2007) or "transient tease" (Schegloff 2007: 44), albeit one in which the boundaries of what is allowable for Jennifer to request are being implicitly negotiated. Instances of other-directed jocular mockery can thus be seen to occasion laughter, partial repetitions, and elaborations, as well as to accomplish particular "unofficial business" in interaction.

In this excerpt, then, we can observe jocular mockery being directed towards someone with whom the speaker - and indeed the other participants - are only just getting acquainted in a "public" interaction where there is large over-hearing audience. While the jocular mockery 
is ostensibly framed as a form of "social sanction" (Drew 1987) in regards to the possibility that Jennifer's request may be going too far (i.e. asking for help with homework), it appears it is primarily oriented to occasioning amusement amongst the participants and the over-hearing audience, and "unofficially" towards implicitly negotiating what is an allowable request on Jennifer's part. We can also observe a range of responses to this other-directed jocular mockery including laughing rejection (line 11) and po-faced rejection (lines 14-16) on the part of the target, and laughing appreciation (line 10) and elaboration of the mocking tease (lines 9,12 ) on the part of another participant following the original tease in line 8.

Importantly, it is the elaborative response on the part of one of the other participants that sees this jocular insert sequence expanded somewhat before returning to the main interactional business of that sequence, namely, Jennifer's request for information.

In the next excerpt from a conversation between two older students, who are classmates as well as friends, candidate examples of jocular mockery directed at self (line 78), as well as another student not present (line 82), arise as they try to establish the referent of the telling or news that Haley wants to share with Sarah.

(5) GCSAusE01: 3:42

(Two female students talking in lunch area at university. Haley is in her late fifties and Sarah is in her forties)

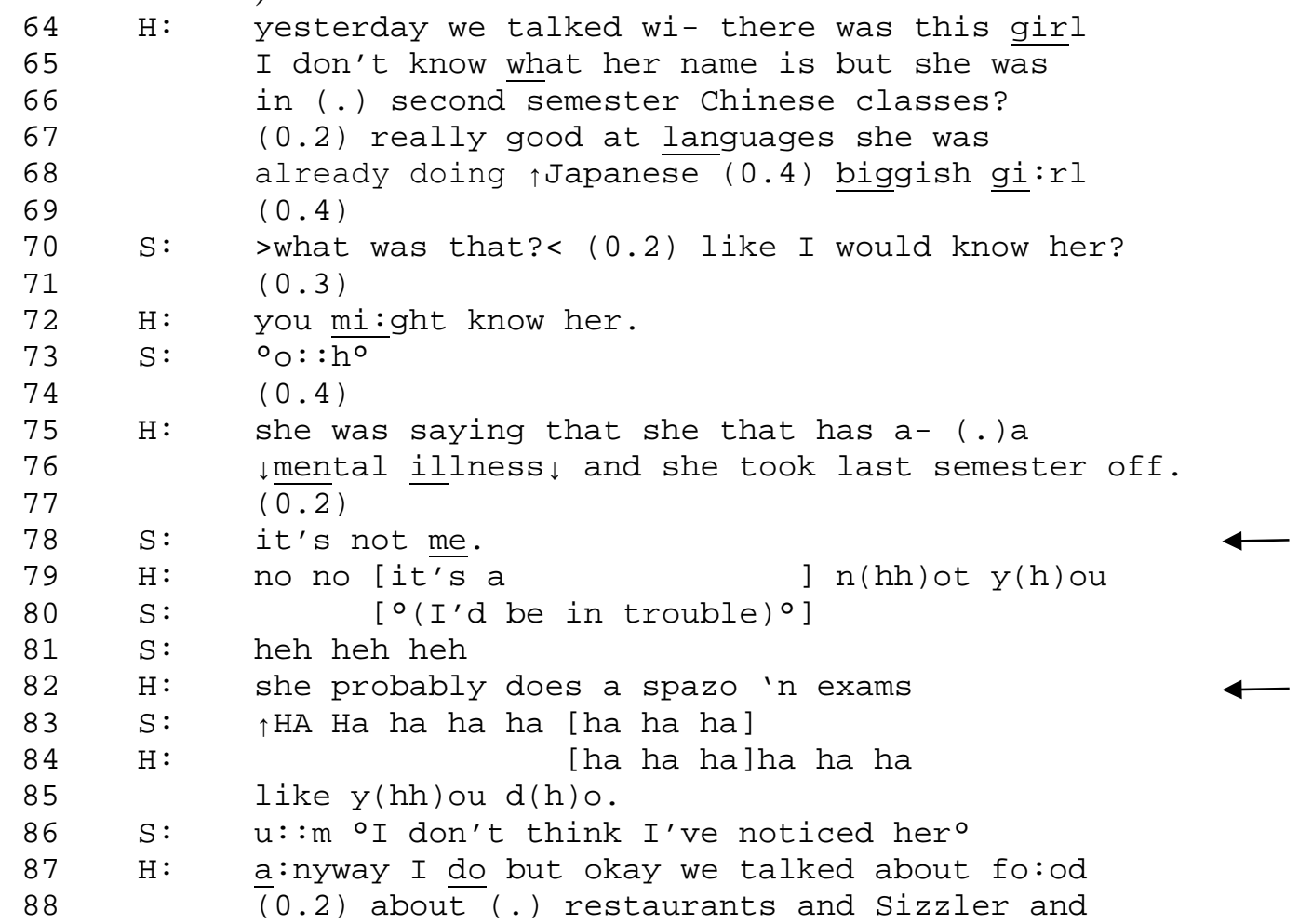

In this excerpt, the telling begins with Haley outlining a discussion she had with one of their classmates in Chinese class the day before. After they have established person reference (lines 64-72). As part of this attempt to establish the referent, Haley goes on to share that the classmate apparently has a "mental illness" (lines 75-76). Notably, this claim is framed as "secret", as she utters the new information, namely, that the classmate apparently has a "mental illness", in a lower-pitched furtive voice (making as if she is afraid others could overhear) (Bergmann 1993: 96; Rodriquez and Ryave 1992). Sarah next responds in line 78 with the truism that it is not her who has the mental illness, thereby presupposing that people (including possibly Haley) could conceivably think she has a mental illness herself. That this constitutes an instance of the pretence of self-deprecation, or non-serious self-mocking is 
apparent from the way in it which arises through a hyper-understanding of Haley's news (Brône 2008), that is, from the way in which Sarah exploits the (ostensible) ambiguity in the specific reference of the third-person pronoun "she" in Haley's previous utterance, as well as the way in which it contrasts with facts known to both participants (i.e. that Sarah does not have any recognised mental illness). It also alludes to the potentially "over-doing" of a furtive tone in Haley's delivery of her revelation about their classmate. The non-serious tenor of Sarah's rebuttal against the charge that she could be seen as having a mental illness becomes apparent in Haley's subsequent response, where she expresses agreement infused with laughter that this is not the case (line 79). The interpolated aspiration particles in " $\mathrm{n}(\mathrm{hh}) \mathrm{ot}$ $y(h) o u$ " also indicates that the claim itself is problematic (Potter and Hepburn 2010), and in this case displays recognition of it as a non-serious one. Sarah also responds with laughter (line 81), thereby sharing in the treatment of the claim as a laughable (Glenn 2003; Holt 2011), before Haley goes on elaborate the mocking sequence by shifting it back to the classmate in question, a non-co-present third party, by suggesting that she has a "spazo", when she has to sit examinations (line 82). Both Sarah and Haley then share in laughter about this possibility marking the suggestion as jocular (lines 83-84), followed by Haley indicating a possible closure to this mocking sequence through the idiomatic phrase "like you do" (Drew and Holt 1998), which is again infused with laughter particles, indicating the problematic nature of such (attributed) behaviour on the part of the classmate. Sarah's subsequent utterance in line 86 is then oriented to Haley's previous claim that she "might know her" (back in line 72), as she claims she has not "noticed her". Haley then prefaces her next utterance in line 87 with "anyway”, a lexical marker of topical discontinuity (Drew 1997: 76), indicating a shift from establishing person reference to a new activity, namely, reporting what she talked about with the classmate. The mocking sequence that began with Sarah's self-directed mockery, and Haley subsequently mocking the third party who is the topic of the sequence, is thus framed by Sarah and Haley as part of a post-expansion of the overall activity sequence of establishing the referent. Moreover, in indicating a shift to another frame through a marker of topical discontinuity, we not only have evidence that this mocking sequence constitutes a side sequence, we have data-internal evidence of a shift back to a serious frame, and thus further indication that the mocking is being understood as nonserious and indeed jocular. In this excerpt, then, we can observe jocular mockery being directed towards self and subsequently a non-co-present third party in a private interaction between two friends (who in this case happen to be middle-aged women). This jocular mockery arises in the course of establishing the referent for a reporting of information about the said person, and thus what is initially framed as self-directed jocular mockery is elaborated through third party-directed jocular mockery which is targeted at the actual referent in question.

While jocular mockery can be directed at self, other participants who are co-present, as well as third parties who are not co-present, as we have seen from the prior two examples, it can also be directed at objects. Yet while object-directed jocular mockery is ostensibly neutral, it can nevertheless have implications for one or more of the parties co-present, as we can observe in the following excerpt. The interaction is between two postgraduate students, in their mid-twenties, who are talking in their office at university about the coffee they're drinking.

(6) ICE-AUS: S1A-020: 0:00

$\begin{array}{lll}1 & \mathrm{~J}: & \text { this coffee looks like } \uparrow \text { up chuck. } \\ 2 & \text { L: } & \text { it does }=\end{array}$

\footnotetext{
${ }^{8}$ Australian English slang for having a fit of spasms, taken from the diminuative form of "spastic", which is itself a vernacular term for a "retarded person".
} 


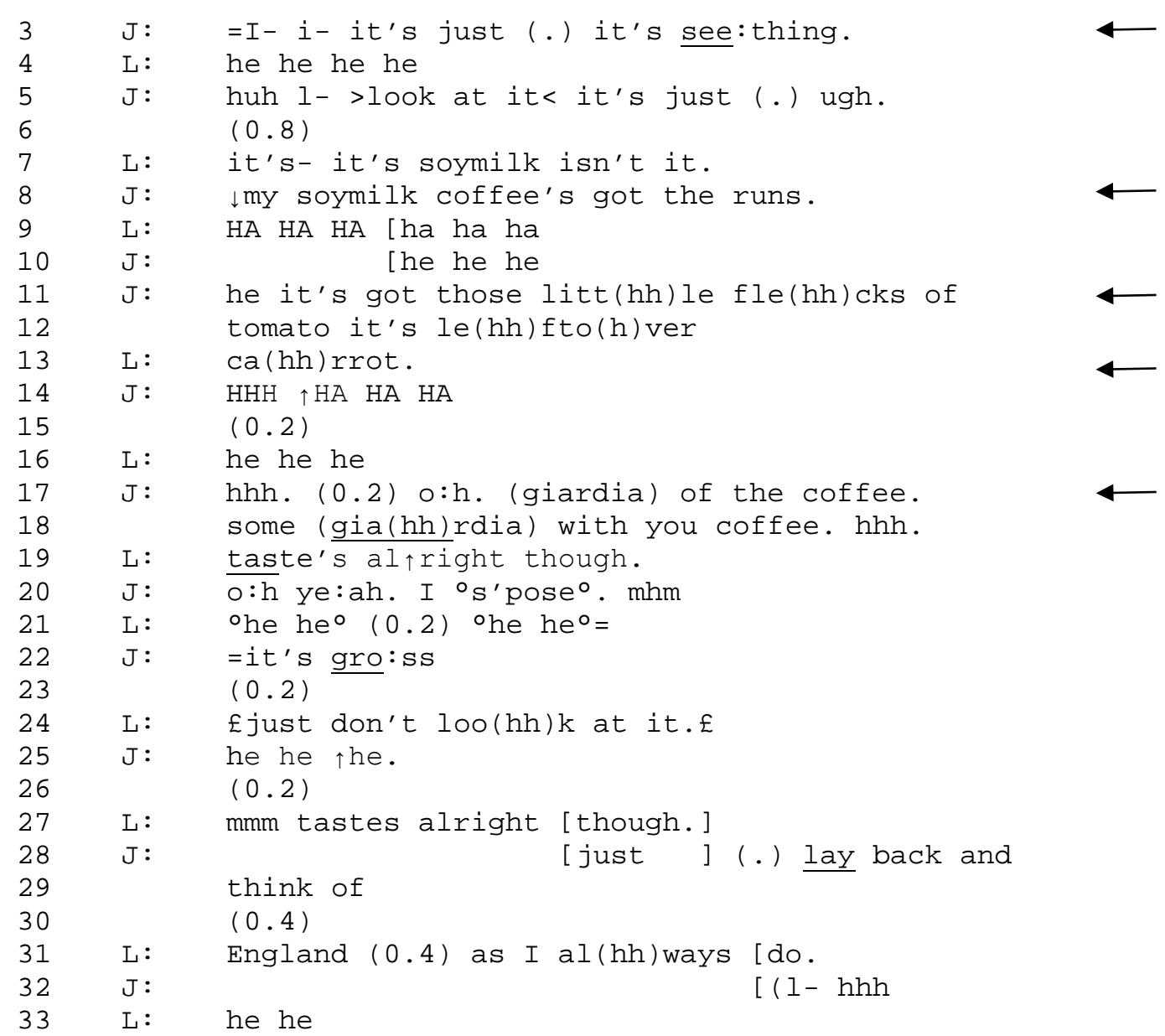

The mocking sequence here begins when Jason casts his coffee as looking like "up chuck" (line 1), and then as "seething" (line 3) and "just ugh" (line 5). Lisa responds with affiliative responses (line 2) and laughter (line 4), thereby marking the proposed characterisations as laughables. She then proposes an account for the appearance of the coffee, namely, it's been made with soymilk (line 7), which then occasions further mocking remarks about the coffee from Jason, namely, the suggestion that it looks like it has "got the runs" (line 8) delivered in a flat, compressed intonation characteristic of "deadpan” delivery (Attardo et al 2003). This occasions laughter from Lisa (line 9), which is then shared in by Aaron (line 10). Jason then further elaborates on this mocking characterisation of the coffee in fairly graphic terms (lines 11-12), an elaboration with which Lisa affiliates through a further suggestion (line 13), which once occasions shared laughter (lines 14, 16), and further elaboration of the mocking (lines 17-18). In this mocking sequence, then, the coffee is characterised as "up chuck", "seething”, as having "the runs", containing "flecks of tomato" and "carrot", and as infected with "giardia", all of which are clearly exaggerations at odds with the reality of the coffee in question (Norrick 2004), and also involve allusions to imagery that is obviously incongruous with enjoying a cup of coffee (Antaki 1998). Alongside the shared laughter then, it is clear from the elaborations by both participants that these instances of mockery are being interactionally achieved as jocular.

Yet notably, while Lisa initially laughs and maintains this jocular frame, she subsequently twice makes the claim that it "tastes alright" (lines 19, 27). And while Jason affiliates with this claim when Lisa first makes it, his response is somewhat hedged ("I suppose") in line 20, and he subsequently casts the coffee as "gross" (line 22). This equivocal affiliative response from Jason with Lisa's stance subsequently occasions a reiterated claim on Lisa's part that the problem is with how the coffee looks (line 24), not with how it tastes (line 27). Notably, 
this stance is first delivered with a smiley voice, or suppressed laughter in turn 22, by which Lisa acknowledges but does not join in with Jason's prior laughter in line 21 (Jefferson 2004b), and also with interpolated laughter particles in "look", by which she indicates her stance is problematic (Potter and Hepburn 2010), here because it potentially disaffiliates with Jason's stance on the coffee as “gross". Once again, Jason implicitly disputes Lisa's stance in characterising the coffee as something to be "endured" without complaint through invoking the idiom, "to lie back and think of England", which is co-constructed through a completion by Lisa (lines 28-31) (cf. Haugh 2010b: 361), and the subsequent laughter treats the idiom as "overdone” (lines 32-33) (Holt 2011). The mocking sequence is also marked for closure through this idiom (Drew and Holt 1998), as they subsequently move on to a different topical focus.

In this excerpt, then, we can observe jocular mockery being directed towards an object in a private interaction between two friends. The jocular mockery becomes the focus of a sequence in its own right, as Jason ups the ante through progressively more incongruous characterisations of the appearance of the coffee. And indeed the sequential mockery differs somewhat from the previous two examples where they part of jocular insert or postexpansion sequences of "serious" action sequences (that is, requesting information in example 4, and establishing person reference in example 5) in that it arguably constitutes an activity sequence in its own right, namely, joking about the coffee they are drinking. Moreover, while Lisa initially affiliates with the mockery and treats it as laughable and indeed jocular through expressing accord, laughter particles, and contributions to elaboration of the mockery, she subsequently takes the stance that while the coffee does not look good, it nevertheless "tastes alright", a stance with which Jason only equivocally affiliates. In the divergence in their stances, then, we have evidence that Lisa may be treating the negative assessments of the coffee as implying a negative assessment of her choice of coffee, and thus potentially a negative assessment of her. Jocular mockery directed at objects is therefore not straightforwardly neutral in regards to co-present participants.

Overall, then, we can observe how the target of jocular mockery can vary between being other-directed, self-directed, third party-directed and object-directed, sometimes within the course of a single interaction. We can also observe how particular design and response features are utilised by participants, not only to frame and treat such instances of mockery as non-serious or jocular, but also in some cases to extend jocular mockery sequences through elaboration and reciprocation/countering of the mockery. The way in which jocular mockery can be extended in this way, or alternatively the (insert/post-expansion) sequence in which the jocular mockery arises is closed, is represented in Figure 1 below.

Figure 1: The interactional dynamics of jocular mockery

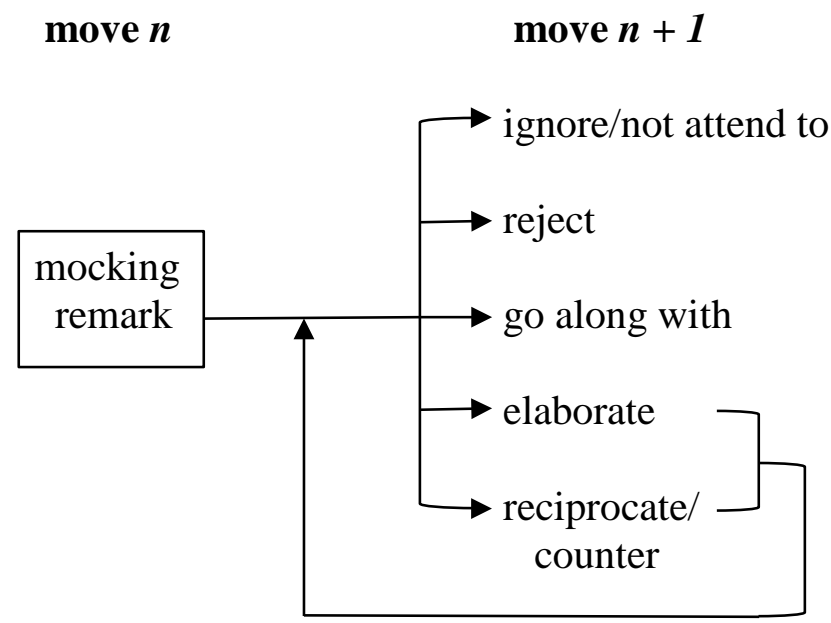


From this figure we can see how a mocking remark at time $n$ in a particular activity sequence can be responded to by a variety of moves at time $n+1$. In instances where the response move involves elaboration or reciprocation/countering of the prior mocking remark this results in yet another cycle of response to a mocking remark, as represented by the line from elaborate and reciprocate/counter back to a further round of response. We examined instances of just such loops of mocking remarks followed by responses that constituted further mocking remarks in all three examples that were examined in this section. However, it is worth noting that while further mocking remarks can be instantiated in responses to prior mocking remarks in the course of extending a mock (insert/post-expansion) sequence, the target of the mockery can shift, as was illustrated above. This model of response moves must therefore be combined within an account of the ways in which targets are construed within the broader participation framework of interaction.

\section{Concluding remarks}

In this paper it has been argued that jocular mockery constitutes a recognisable and recurrent practice in interactions amongst Anglo-Australian speakers of English. The claim that jocular mockery is not only a recognisable but also a recurrent practice in everyday interactions amongst (Anglo-)Australian speakers of English was based on a collection of 135 instances of jocular mockery that were sourced from a number of different corpora, most of which are now freely available through the Australian National Corpus. A preliminary model for analysing the interactional dynamics of jocular mockery was also proposed on close qualitative analysis of examples from this collection. An implicit methodological claim underpinning this paper has thus been that close analysis of locally situated interactions using methods from interactional pragmatics can be complemented by emerging work in corpusassisted pragmatics (Haugh and Chang 2013; Walsh 2013; cf. Partington 2008; SantamaríaGarcía 2011). Yet while combining analytical insights from interactional pragmatics with the generalizability that corpus pragmatics potentially offers arguably has considerable potential, there is still considerable work remaining to allow more effective interrogation of corpora for pragmatic phenomena (Deppermann 2010; Schalley, Musgrave and Haugh this issue).

Studies such as the one here thus only open the door, but do not yet step from corpus-assisted pragmatics through to a corpus pragmatics proper. However, it does nevertheless illustrate the considerable analytical traction to be gleaned from drawing together a meta-collection of different spoken corpora as implemented in the case of the Australian National Corpus.

\section{Transcription conventions}

[ ] overlapping speech

(0.5) numbers in brackets indicate pause length

(.) micropause

: elongation of vowel or consonant sound $\$

underlining contrastive stress or emphasis

- $\quad$ word cut-off

$=\quad$ latched utterances

. falling or final intonation

? $\quad$ rising intonation

$\dot{d} \quad$ falling then rising intonation

, 'continuing' intonation 


$\begin{array}{ll}\downarrow \uparrow & \text { sharp falling/rising intonation } \\ \text { CAPS } & \text { markedly louder } \\ \circ \circ & \text { markedly soft } \\ \text { hhh } & \text { hearable in-breath } \\ \text { hhh } & \text { hearable aspiration } \\ \text { ha he huh } & \text { laughter particles } \\ \text { n(hh)o } & \text { interpolated laughter particles (interpolated particles of aspiration) } \\ £ £ & \text { hearably smiling voice (i.e. suppressed laughter) } \\ >< & \text { talk is compressed or rushed } \\ <> & \text { talk is markedly slowed or drawn out } \\ (\quad) & \text { blank space in parentheses indicates uncertainty about the transcription }\end{array}$

\section{Acknowledgements}

I would like to thank the two anonymous reviewers for their very constructive comments on an earlier version of this work.

\section{References}

Adetunji, A. 2013. A discursive construction of teasing in football fandom: the context of the South-Western Nigerian viewing centre. Discourse and Society, 24:147-62.

Antaki, C. 1998. "Identity ascriptions in their time and place: 'Fagin' and 'The terminally dim’.” In Identities in Talk, Edited by: Antaki, C and Widdicombe, S. 71-86. London: Sage.

Arundale, R. 2010. Constituting face in conversation: face, facework and interactional achievement. Journal of Pragmatics, 42:2078-105.

Attardo, S, Eisterhold, J, Hay, J and Poggi, I. 2003. Multimodal markers of irony and sarcasm. Humor, 16:243-60.

Beach, W and Glenn, P. 2011. "Bids and responses to intimacy as 'gendered' enactments". In Conversation and Gender, Edited by: Speer, SA and Stokoe, E. 210-28. Cambridge: Cambridge University Press.

Béal, C and Mullan, K. forthcoming. "Issues in conversational humour from a cross-cultural perspective: comparing French and Australian corpora”. In Cross-culturally Speaking, Speaking Cross-culturally, Edited by: Béal, C, Mullan, K and Peeters, B. Newcastleupon-Tyne: Cambridge Scholars Press.

Bertrand, R and Priego-Valverde, B. 2011. Does prosody play a specific role in conversational humour? Pragmatics and Cognition, 19:333-56.

Bergmann, J. 1993. Discreet Indiscrections. The Social Organisation of Gossip. Berlin: Mouton de Gruyter.

Blythe, J. 2012. From passing-gesture to 'true' romance: kin-based teasing in Murriny Patha conversation. Journal of Pragmatics, 44:508-28.

Boxer, D and Cortés-Conde, F. 1997. From bonding to biting: conversational joking and identity display. Journal of Pragmatics, 27:275-94.

Brône, G. 2008. Hyper- and misunderstanding in interactional humour. Journal of Pragmatics, 40:2027-61.

Butler, C. 2007. From bite to nip: the dialogic construction of teases. Texas Linguistic Forum, 50:22-34.

Culpeper, J. 1996. Towards an anatomy of impoliteness. Journal of Pragmatics, 25:349-67.

Depperman, A. 2010. "Future prospects of research on prosody: the need for publicly available corpora”. In Prosody in Interaction, Edited by: Barth-Weingarten, D, Reber, E and Selting, M. 41-47. Amsterdam: John Benjamins. 
Drew, P. 1987. Po-faced receipts of teases. Linguistics, 25:219-53.

—. 1997. 'Open' class repair initiators in response to sequential sources of troubles in conversation. Journal of Pragmatics, 28:69-101.

Drew, P and Holt, E. 1998. Figures of speech: figurative expressions and the management of topic transition in conversation. Language in Society, 27:495-523.

Dynel, M. 2007. “Joking aside: sociopragmatic functions of conversational humour in interpersonal communication”. In Current Trends in Pragmatics, Edited by: Cap, P and Nijakowska, J. 246-68. Newcastle: Cambridge Scholars Publishing.

—. 2008. No aggression, only teasing: the pragmatics of teasing and banter. Lodz Papers in Pragmatics, 4:241-61.

Edwards, D. 2000. Extreme case formulations: softeners, investment, and doing nonliteral. Research on Language and Social Interaction, 33:347-73.

Everts, E. 2003. Identifying a particular family humour style: a sociolinguistic discourse analysis. Humor, 16:369-412.

Ford, C and Fox, BA. 2010. "Multiple practices for constructing laughables”. In Prosody in Interaction, Edited by: Barth-Weingarten, D, Reber, E and Selting, M. 339-68. Amsterdam: John Benjamins.

Fox, K. 2004. Watching the English. The Hidden Rules of English Behaviour, London: Hodder.

Franzén, AG and Aronsson, K. 2013. Teasing, laughing and disciplinary humour: staff-youth interaction in detention home treatment. Discourse Studies, 15:167-83.

Gardner, R. 2002. When Listeners Talk: Response Tokens and Listener Stance, Amsterdam: John Benjamins.

Glenn, P. 1991/1992. Current speaker initiation of two-party shared laughter. Research on Language and Social Interaction, 25:139-62.

—. 2003. Laughter in interaction, Cambridge: Cambridge University Press.

Goddard, C. 2006. “'Lift your game, Martina!” - Deadpan jocular irony and the ethnopragmatics of Australian English”. In Ethnopragmatics: Understanding Discourse in Cultural Context, Edited by: Goddard, C. 65-97. Berlin: Mouton de Gruyter.

—. 2009. Not taking yourself too seriously in Australian English: semantic explications, cultural scripts, corpus evidence. Intercultural Pragmatics, 6:29-53.

Grainger, K. 2004. Verbal play on the hospital ward: solidarity or power? Multilingua, 23:3959.

Greer, T, Usui, Y, Kato, T and Taniguchi, H. 2005. Suppressing laughter in the display of (dis)affiliation. Kobe Daigakui Kokusai Komyunikeeshon Sentaa Ronshuu (Kobe University International Communication Centre Bulletin), 2:27-42.

Haakana, M. 2002. Laughter in medical interaction: from quantification to analysis, and back. Journal of Sociolinguistics, 6:207-35.

Harwood, D. 2010. The phenomenon of sibling teasing: three mothers' perceptions of their children's teasing behaviours. Journal of Research in Childhood Education, 24:36685.

Haugh, M. 2009. "Designing and multimodal spoken component of the Australian National Corpus”. In Selected Proceedings of the 2008 HSCNet Workshop on Designing the Australian National Corpus: Mustering Languages, Edited by: Haugh, M, Burridge, K, Mulder, J and Peters, P. 74-86. Sommerville, MA: Cascadilla Proceedings Project.

—. 2010a. Jocular mockery, (dis)affiliation and face. Journal of Pragmatics, 42:2106-19.

—. 2010b. "Co-constructing what is said in interaction". In The Role of Data at the Semantics-Pragmatics Interface, Edited by: Nemeth T, E and Bibok, K. 349-80. Berlin: Mouton de Gruyter. 
—. 2011. "Humour, face and im/politeness in getting acquainted”. In Situated Politeness, Edited by: Davies, B, Haugh, M and Merrison, A. 165-84. London: Continuum.

—. 2012. “Conversational interaction”. In The Cambridge Handbook of Pragmatics, Edited by: Allan, K and Jaszczolt, KM. 251-74. Cambridge: Cambridge University Press.

Haugh, M and Bousfield, D. 2012. Mock impoliteness, jocular mockery and jocular abuse in Australian and British English. Journal of Pragmatics, 44:1099-114.

Haugh, M and Chang, W. 2013. "Collaborative creation of spoken language corpora”. In Pragmatics and Language Learning Volume 13, Edited by: Greer, T Kite, Y and Tatsuki, D. 119-46. Honolulu: National Foreign Language Resource Centre, University of Hawai'i.

Hepburn, A and Bolden, GB. 2012. “The conversation analytic approach to transcription”. In The Handbook of Conversation Analysis, Edited by: Stivers, T and Sidnell, J. 57-76. Oxford: Blackwell.

Holt, E. 2007. “'I’m eyeing your chop up mind’: reporting and enacting”. Reporting Talk: Reported Speech in Interaction, Edited by: Holt, E and Clift, R. 47-80. Cambridge: Cambridge University Press.

—. 2010. The last laugh: shared laughter and topic termination. Journal of Pragmatics, 42:1513-25.

—. 2011. On the nature of 'laughables': laughter as a response to overdone figurative phrases. Pragmatics, 21:393-410.

Jefferson, G. 1979. "A technique for inviting laughter and its subsequent acceptancedeclination”. Everyday Language: Studies in Ethnomethodology, Edited by: Psathas, G. 79-95. New York: Irvington.

—. 2004a. "Glossary of transcript symbols with an introduction". In Conversation Analysis: Studies from the First Generation, Edited by: Lerner, G. 13-23. Amsterdam: John Benjamins.

—. 2004b. A note on laughter in 'male-female' interaction. Discourse Studies, 6:117-33.

Jefferson, G, Sacks, H and Schegloff, E. 1987. "Notes on laughter in the pursuit of intimacy". In Talk and Social Organisation, Edited by: Button, G and Lee, J. 152-205. Clevedon, UK: Multilingual Matters.

Keltner, D, Capps, L, Kring, A, Young, R and Heerey, E. 2001. Just teasing: a conceptual analysis and empirical review. Psychological Bulletin, 127:229-48.

Kotthoff, H. 1996. Impoliteness and conversational joking: on relational politics. Folia Linguistica, 30:299-325.

Lampert, MD and Ervin-Tripp, S. 2006. Risky laughter: teasing and self-directed joking among male and female friends. Journal of Pragmatics, 38:51-72.

Leech, G. 1983. Principles of Pragmatics, London: Longman.

Levinson, S. 2012. “Action formation and ascription”. In Handbook of Conversation Analysis, Edited by: Stivers, T and Sidnell, J. 103-30. Malden, MA: Wiley-Blackwell.

Lytra, V. 2007. Teasing in contact encounters: frames, participant positions and responses. Multilingua, 26:381-408.

Mills, S. 2003. Gender and Politeness, Cambridge: Cambridge University Press.

Norrick, N. 1993. Conversational Joking. Humour in Everyday Talk, Bloomington, IN: Indiana University Press.

—. 1994. Involvement and joking in conversation. Journal of Pragmatics, 22:409-30.

—. 2004. Hyperbole, extreme case formulation. Journal of Pragmatics, 36:1727-39.

Norrick, N and Spitz, A. 2008. Humour as a resource for mitigating conflict in interaction. Journal of Pragmatics, 40:1661-86.

Partington, A. 2008. Teasing at the White House: a corpus-assisted study of face work in performing and responding to teases. Text and Talk, 28:771-72. 
Pawluk, C. 1989. Social construction of teasing. Journal for the Theory of Social Behavior, 19:145-67.

Pomerantz, A. 1986. Extreme case formulations: a way of legitimizing claims. Human Studies, 9:219-29.

Potter, J and Hepburn, A. 2010. Putting aspiration into words: 'laugh particles', managing descriptive trouble and modulating action. Journal of Pragmatics, 42:1543-55.

Rodriquez, N and Ryave, A. 1992. The structural organization and micropolitics of everyday secret telling interactions. Qualitative Sociology 15:297-318.

Queen, R. 2005. "How many lesbians does it take...”: Jokes, teasing, and the negotiation of stereotypes about lesbians. Journal of Linguistic Anthropology, 15:239-57.

Santamaría-García, C. 2011. Bricolage assembling. CL, CA and DA to explore agreement. International Journal of Corpus Linguistics, 16:345-70.

Schalley, AC, Musgrave, S and Haugh, M. 2013. Accessing phonetic variation in spoken language corpora thorugh non-standard orthography. Australian Journal of Linguistics, this volume

Schegloff, E. 2001. Getting serious: joke >> serious 'no'. Journal of Pragmatics, 33:1947-55.

—. 2007. Sequence Organization in Interaction, Cambridge: Cambridge University Press.

Schenkein, JN. 1972. Towards an analysis of natural conversation and the sense of heheh. Semiotica, 6:344-77.

Schnurr, S. 2009. Constructing leader identities through teasing at work. Journal of Pragmatics, 41:1125-38.

Sidnell, J. 2011. “'D’you understand that honey?': Gender and participation in conversation”. In Conversation and Gender, Edited by: Speer, SA and Stokoe, E. 183-209. Cambridge: Cambridge University Press.

Stivers, T and Robinson, JD. 2006. A preference for progressivity in interaction. Language in Society, 35:367-92.

Straehle, C. 1993. “'Samuel?' 'Yes dear?' Teasing and conversational rapport”. In Framing in Discourse, Edited by: Tannen, D. 210-30. Oxford: Oxford University Press.

Walsh, S. 2013. "Corpus linguistics and conversation analysis at the interface: theoretical perspectives, practical outcomes”. In Yearbook of Corpus Linguistics and Pragmatics Vol 1, Edited by: Romero-Trillo, J. 37-51. Berlin: Springer.

$\mathrm{Yu}, \mathrm{C}$. 2013. Two interactional functions of self-mockery in everyday English conversations: a multimodal analysis. Journal of Pragmatics, 50:1-22. 